\title{
Research of Pure Bending Beam Based on Workbench and Experimental Technology
}

\author{
Zhongfang Li and Yinhu Qiao* \\ Anhui science and technology university, college of mechanical engineering, fengyang, anhui, 233100, China \\ ${ }^{*}$ Corresponding author
}

\begin{abstract}
In this paper, the ansys stress simulation technology under workbench environment is applied to the normal stress on the cross section analysis of pure bending of curved beam and beam deformation analysis, the results of simulation image intuitive shows the normal stress distribution on cross section pure bending of curved beam and beam axis in bending in-plane deformation characteristics. By means of strain testing equipment and mechanical test bench, the normal stress distribution on the cross section of pure bending beam was tested. The simulation results and experimental results are consistent with the theoretical analysis results.
\end{abstract}

Keywords — workbench; pure bending beam; experiment

\section{INTRODUCTION}

Workbench is a collaborative simulation environment proposed by ANSYS to solve the heterogeneous problem of CAE software in the process of product development. Compared with Mechanical APDL, workbench is more mature and humanized in modeling and compatibility with other cad software, which makes it more widely used and more quickly popularized. The research of pure bending beam is the foundation of general transverse bending beam. The finite element software is widely used in all kinds of beam structures [1]-[6]. In this paper, the ansys software based on workbench platform is applied to the stress analysis of pure bending beam, which can show the deformation law and stress distribution law of pure bending beam more intuitively. The experimental results also confirm the simulation results.

\section{Distribution of Normal Stress On Cross Section of Pure Bending Beam and Deformation law of Pure BENDING BEAM}

\section{A. Formula of Normal Stress Distribution on Cross Section} of Pure Bending Beam

On the premise that the normal stress is not greater than the material's proportional limit, the normal stress distribution on the cross section of pure bending beam is as follows:

$$
\sigma=\frac{M y}{I_{z}}
$$

Where $\mathrm{M}$ is the moment on the cross section,y is the distance from any point in the cross section to the neutral axis, $I_{z}$ is the moment of inertia of the cross section to the principal axis of inertia (not specifically the $z$ axis).
Deformation law of pure bending beam

On the premise that the material satisfies Hooke's law, the formula of the deformation of the pure bending beam is as follows:

$$
\frac{d^{2} w}{d t^{2}}=\frac{M}{E I_{z}}
$$

Among them, $E I_{z}$ is the bending stiffness of the beam.

III. RESEARCH ON NORMAL STRESS DiSTRIBUTION ON Cross Section of Pure Bending Beams and Deformation ANAlysis of PuRE BENDING BEAMS BASED ON WORKBENCH

\section{A. Modeling}

Solid beam with rectangular section made of structural steel, material density is $7850 \mathrm{~kg} / \mathrm{m}^{3}$, the modulus of elasticity is $E=2.0 e 11 p a$, Size $20 \times 30 \times 200 \mathrm{~mm}$, The two ends are subjected to the action of $300 \mathrm{~N}$ m bending moment. Figure I is the modeling diagram of the beam., (a) is the geometric structure, (b) is the mesh division result, (c) adds the fixed end constraint, (d) to apply the force couple load.

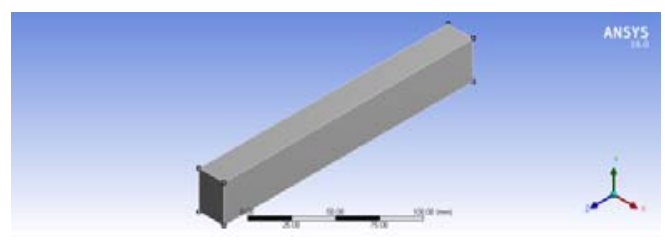

(a) Geometry

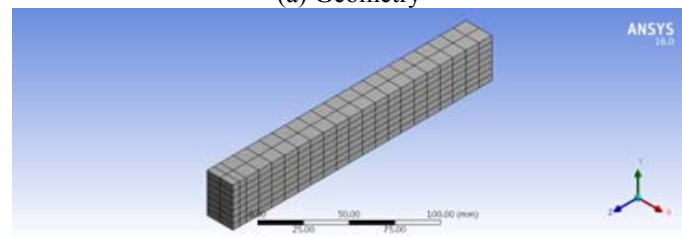

(b) Grid Division Results

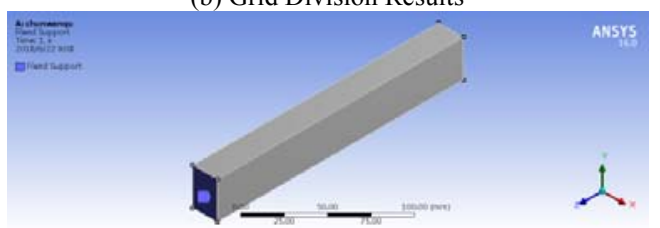

(c) Adding fixed end constraint 


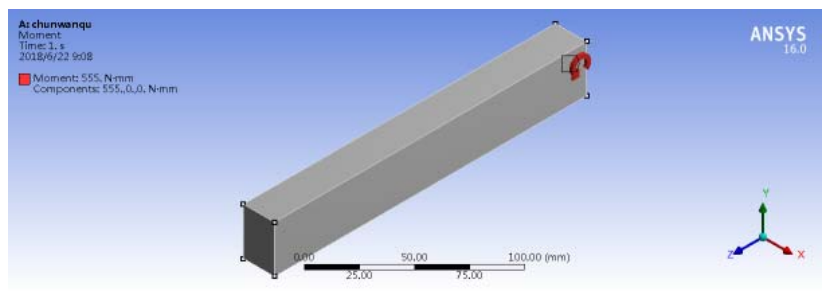

(d) Applying couple load

FIGURE I. FINITE ELEMENT MODELING PROCESS

B. Distribution of Normal Stress on Cross Section of Pure Bending Beam Based on Workbench

Figure II and III show the normal stress distribution of the beam along the axial direction. The distribution of normal stress on the cross section of beam is highlighted in Figure III. It can be clearly seen in the four sides of the beam:

1) The longer the distance from the neutral axis, the greater the normal stress along the axis.

2) The absolute value of normal stress on top and bottom reaches the maximum value of $124 \mathrm{MPA}$.

3) On the tensile side, the normal stress is tensile stress, which is greater than 0 ;

4) On the compression side, the normal stress is compressive stress, less than 0 .

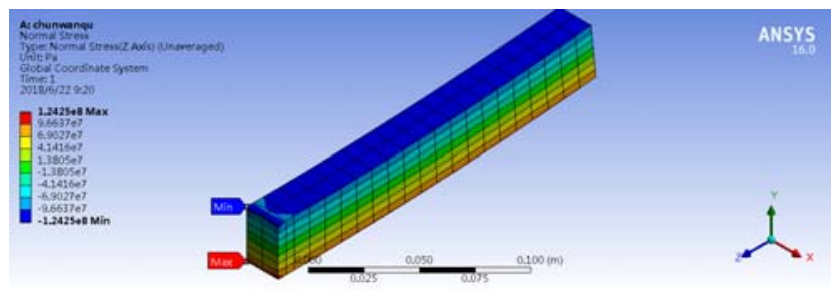

FIGURE II. STRESS DISTRIBUTION IN AXIAL DIRECTION OF BEAM

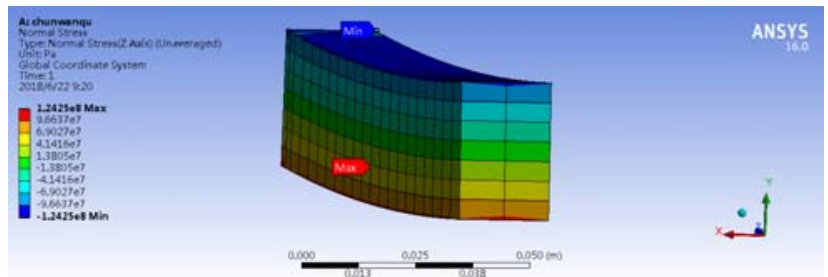

FIGURE III. NORMAL STRESS DISTRIBUTION ON CROSS SECTION OF BEAM

\section{Deformation Analysis of Pure Bending Beam Based on Workbench}

Figure IV shows the deformation of all points on the beam along the y direction.

1) The deflection of the point in the same cross section along the $y$ direction is the same;

2) The deflection of the fixed end of the beam is 0 , the deflection of the free end is the largest, and the deflection is the same as that of the bending moment.

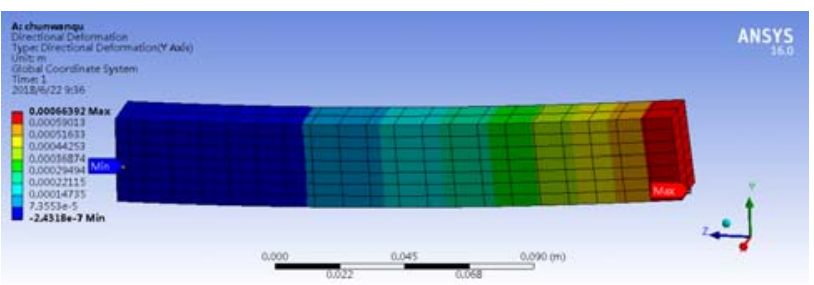

FIGURE IV. DEFORMATION OF POINTS ON BEAM ALONG Y DIRECTION

\section{EXPERIMENTAL ANALYSIS}

The size of the beam is $480 \times 20 \times 40$, and the restraint mode is simply supported beam, which is thrust upward by a small short beam on the bottom of the beam. According to the knowledge of material mechanics, pure bending deformation occurs in the middle beam section. Three strain gauges are attached to one side of the beam, and one strain gauge is attached to the top surface and the bottom surface. The normal stress distribution on the cross section of pure bending section of beam was measured. (See Figure V)

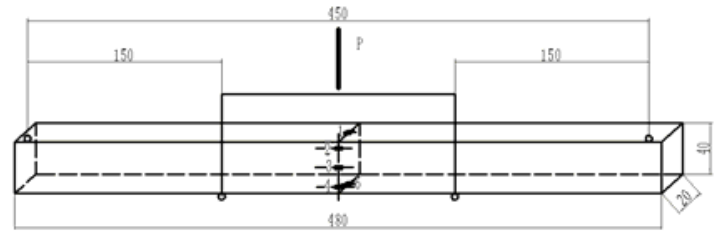

FIGURE V. DIMENSIONS AND STRAIN GAUGE POSITION OF PURE BENDING BEAM

Table I shows the distance between the five strain gauges and the neutral axis, as well as the cross section shape, size and material parameters of the beam.

\section{TABLE I. PARAMETERS OF BEAMS AND STRAIN GAUGES}

\begin{tabular}{|c|c|c|}
\hline \multicolumn{2}{|c|}{$\begin{array}{l}\text { Strain gauge to neutral layer } \\
\qquad(\mathrm{mm})\end{array}$} & $\begin{array}{c}\text { Dimensions and related parameters of } \\
\text { beams }\end{array}$ \\
\hline 1 & -20 & $b=20 \mathrm{~mm}$ \\
\hline 2 & -15 & $\begin{array}{l}h=40 \mathrm{~mm} \\
t=450 \mathrm{~mm}\end{array}$ \\
\hline 3 & 0 & $\alpha=150 \mathrm{mmm}$ \\
\hline 4 & 15 & $E=203 G P a$ \\
\hline 5 & 20 & $I_{z}=b h^{3} / 12=1.067 \times 10^{-7} \mathrm{~m}^{4}$ \\
\hline
\end{tabular}

In order to obtain more accurate test results, the difference average method is used for data processing. The average strain change at $500 \mathrm{~N}$ is taken as the experimental value, as shown by the blackbody data. (See Table II) 
TABLE II. STRAIN TEST RESULTS AND STRESS CALCULATION

\begin{tabular}{|c|c|c|c|c|c|c|c|c|c|c|}
\hline \multirow{3}{*}{$\begin{array}{c}\text { load } \\
(N) \\
\text { Collection point }\end{array}$} & \multicolumn{2}{|c|}{1} & \multicolumn{2}{|c|}{2} & \multicolumn{2}{|c|}{3} & \multicolumn{2}{|c|}{4} & \multicolumn{2}{|c|}{5} \\
\hline & \multicolumn{10}{|c|}{ Measuring point strain $(\mu \varepsilon)$} \\
\hline & $\begin{array}{c}\text { indicatio } \\
\mathrm{n}\end{array}$ & $\Delta \varepsilon$ & $\begin{array}{c}\text { indicati } \\
\text { on }\end{array}$ & $\Delta \varepsilon$ & $\begin{array}{c}\text { indicatio } \\
n\end{array}$ & $\Delta \varepsilon$ & $\begin{array}{c}\text { indicatio } \\
n\end{array}$ & $\Delta \varepsilon$ & $\begin{array}{c}\text { indicatio } \\
\mathrm{n}\end{array}$ & $\Delta \varepsilon$ \\
\hline 500 & 35 & \multirow{2}{*}{35} & 26 & \multirow{2}{*}{27} & 0 & \multirow{2}{*}{0} & -25 & \multirow{2}{*}{-27} & -35 & \multirow{2}{*}{-35} \\
\hline 1000 & \multirow{2}{*}{70} & & 53 & & \multirow{2}{*}{1} & & -52 & & \multirow{2}{*}{-70} & \\
\hline & & 32 & & 26 & & 1 & & -25 & & -33 \\
\hline 1500 & 102 & \multirow{2}{*}{35} & 77 & \multirow{2}{*}{26} & 0 & & -77 & \multirow{2}{*}{-26} & -103 & \\
\hline \multirow{2}{*}{2000} & \multirow{2}{*}{137} & & \multirow{2}{*}{105} & & \multirow{2}{*}{0} & 0 & & & & \\
\hline & & 36 & & 26 & & -1 & & -27 & & -36 \\
\hline 2500 & 173 & & 131 & & -1 & & -132 & & -173 & \\
\hline $\begin{array}{c}\text { mean increment } \\
\Delta P=500\end{array}$ & & 34.5 & & 26.3 & & 0 & & -26.8 & & -34.5 \\
\hline $\begin{array}{c}\text { Stress } \\
\text { (experimental } \\
\text { value) }\end{array}$ & & & & & & & & & & \\
\hline $\begin{array}{c}\text { Stress } \\
\text { (theoretical } \\
\text { value) }\end{array}$ & & & & & & & & & & \\
\hline
\end{tabular}

The measured results of each strain gauge are micro-strain. The experimental stress values of each point are obtained by conversion and using Hooke's law, and the error is less than $3 \%$ compared with the theoretical value. The experimental and theoretical results show that the normal stress on the cross section of pure bending beam is proportional to the distance from this point to the neutral axis, the normal stress on the neutral axis is zero, and the stress on the top and bottom is the largest.

\section{CONCLUSION}

In this paper, the numerical analysis of pure bending beam is carried out on the basis of Ansys software in workbench environment. The deformation law of pure bending beam and the distribution law of normal stress on cross section are shown. The stress measurement on the cross section of pure bending beam is realized by means of stress test equipment and mechanical test rig. The experimental and simulation results are in agreement with the theoretical values. The Workbench can help the scientific and technical workers to better apply the finite element technology to the strength analysis and deformation analysis of engineering equipment and mechanical equipment. Mechanics educators can also apply this technology to teaching. It can show the deformation rules and stress distribution rules of the components more intuitively.

\section{ACKNOWLEDGEMENT}

This paper is funded by the projects "Key R \& D Project of Anhui Science and Technology Department (1704a0902058); Major Project of Natural Science Foundation of Anhui Education Department (KJ2017ZD44); key Construction discipline of Anhui Institute of Science and Technology (AKZDXK2015C03); stable Talent Foundation of Anhui Institute of Science and Technology (JXWD201602)".

\section{REFERENCES}

[1] Lu Huabin, Han Jinhua. Experimental simulation of normal stress of pure bending beam based on Abaqus [J]. Manufacturing automation, 2012, 34(01):90-93.

[2] Yang Chuangzhan, Liu Jie, Mu Huiyong, Zhang Panbo. Simulation analysis of normal stress of pure bending beam based on ANSYS [J]. Mechanical manufacturing and automation, 2014, 43(01):109-110+120.

[3] Li Fang, Wang Ni, Gu Xiaomei. Practice and research on experimental expansion of pure bending beam [J]. Experimental science and technology, 2013, 11(01):39-40+123.

[4] Sun Yi, Dong Weimin, Yang Qianhong. Experimental study on mechanics of materials based on finite element analysis [J]. New technology and new technology, 2011(11):61-63.

[5] Qiu Ling, Zhu Weixuan. Computer simulation of pure bending beam experiment $[\mathrm{J}]$. Experimental Technology and Management, 2007(10):291-293.

[6] Pu Guangyi, Song Guanglei. Organic combination of experimental teaching of mechanics of materials with finite element method [J]. Human resources management, 2010(01):111+113. 